\title{
A paradigm shift for extracellular vesicles as small RNA carriers: from cellular waste elimination to therapeutic applications
}

\author{
Keitaro Hagiwara • Takahiro Ochiya • \\ Nobuyoshi Kosaka \\ Published online: 12 October 2013 \\ (C) The Author(s) 2013. This article is published with open access at Springerlink.com
}

\begin{abstract}
RNA interference (RNAi) is an important avenue for target-specific gene silencing that is mainly performed by either small interfering RNAs (siRNAs) or microRNAs (miRNAs). This novel method is rapidly becoming a powerful tool for gene therapy. However, the rapid degradation of siRNAs and miRNAs and the limited duration of their action in vivo call for an efficient delivery technology. Recently, increasing attention has been paid to the use of extracellular vesicles (EVs) as delivery systems. The use of EVs as small RNA carriers has multiple advantages over conventional delivery systems. In this review, we summarize recent findings regarding the potential application of EVs as small RNA delivery systems. Moreover, we focus on some of the obstacles to EV-based therapeutics.
\end{abstract}

Keywords Extracellular vesicles $\cdot$ Exosome $\cdot$ RNAi miRNA $\cdot$ siRNA $\cdot$ Drug delivery system

\section{Introduction}

Therapeutic strategies are essential for curing human diseases [1]. Therefore, a continuous search for new approaches to tackle human diseases is important. The discovery of RNAi, which is mainly performed by either small interfering RNAs (siRNAs) that degrade mRNA or microRNAs (miRNAs) that attenuate translation, for target-specific gene silencing has

\footnotetext{
K. Hagiwara $\cdot$ T. Ochiya $\cdot$ N. Kosaka $(\bowtie)$

Division of Molecular and Cellular Medicine, National Cancer

Center Research Institute, 5-1-1, Tsukiji, Chuo-ku,

Tokyo 104-0045, Japan

e-mail: nkosaka@ncc.go.jp

K. Hagiwara

Department of Biological Sciences, Tokyo Institute of Technology,

4259 Nagatsuta-cho, Midori-ku, Yokohama 226-8501, Japan
}

rapidly created a powerful tool for the exploration of pathogenesis of human disease [2-4]. The identification of these remarkable molecular pathways has manifested a new field of gene therapy. However, the clinical use of miRNA or siRNA entails at least two critical steps: delivery of miRNA or siRNA to the appropriate tissues and subsequent maintenance and expression. A key goal of target-specific RNAi delivery technology for several diseases is the development of delivery systems directed at the target tissues only. Currently, there are many types of drug delivery systems. However, these methods have several limitations such as the lack of delivery systems that are safe, efficient, tissue specific and that do not cause immune and inflammatory responses when they are used in vivo.

It has been well known for decades that miRNAs can be detected in human body fluids such as plasma, saliva, and breast milk, although ribonucleases circulate throughout the body [5-9]. This finding suggested that miRNAs are inserted into RNase-resistant lipid vesicles before secretion. Indeed, it has been reported that miRNAs exist in extracellular vesicles such as exosomes and microvesicles [10]. Exosomes and microvesicles are produced by many cell types such as cancer cells [11], dendritic cells [12], intestinal epithelial cells [13], T cells [14], and B cells [15]. One current definition is that exosomes are small membrane vesicles $(40-100 \mathrm{~nm})$ from multivesicular endosomes, whereas microvesicles (50-1, $000 \mathrm{~nm}$ ) are generated by budding at the plasma membrane [16]. However, no current consensus exists on the precise definition of exosomes and microvesicles. Therefore, we used "extracellular vesicles (EVs)" as all types of vesicles in the extracellular space throughout the paper as recommended by the "International Society for Extracellular Vesicles," which is the international exosomes and microvesicles community. Trams et al. initially reported in 1981 that exfoliated membrane vesicles with 5'-nucleotidase activity can detect from various normal and neoplastic cell lines (Table 1) [17]. 
Table 1 Historical key developments in studies of the EVs after 1980s

\begin{tabular}{lll}
\hline Year & Milestone discovery & References \\
\hline 1981 & EVs were reported & {$[17]$} \\
1985 & EVs were detected by electron microscopy & {$[18]$} \\
1996 & EVs presenting immune antigen were discovered & {$[15]$} \\
1998 & RNAi was discovered & {$[3]$} \\
2007 & Valadi et al. first reported that EVs contain mRNA & {$[10]$} \\
2010 & and miRNA & Three groups confirmed that miRNAs in EVs \\
\multirow{2}{2011}{} & Delivery of siRNA by EVs in vivo was demonstrated & {$[20-22]$} \\
\hline
\end{tabular}

Moreover, Pan et al. demonstrated the existence of 50-nm membrane vesicles secreted from sheep reticulocytes using electron microscopy [18]. Since then, EVs have been considered as waste disposal agents for cells because EVs are similar to apoptotic blebs. However, apoptotic blebs are rapidly cleared in circulation by phagocytosis due to phosphatidylserine exposure [19]. In addition, EVs became of interest for immunologists in the 1990s. Raposo et al. showed that EVs derived from both human and murine B lymphocytes activated $\mathrm{T}$ cell immune responses [15]. Most importantly, Valadi et al. demonstrated that EVs derived from various cell types contain RNA including mRNA and miRNA in 2007 [10]. In addition, three groups independently discovered that EVs contain miRNA transferred between cells and subsequently suppress the target genes in recipient cells [20-22]. They demonstrated that miRNAs traveled between cells using EVs, and these RNAs are functional in transmitted recipient cells [20-22]. In particular, Pegtel et al. demonstrated that total RNAs from $2 \times 10^{4}$ cells of monocyte-derived dendritic cells (MoDC) co-cultured with EBV-transformed lymphoblastoid $B$ cells (LCL) contained over thousands of individual EBVmiRNA copies as little as $500 \mathrm{pg}$ of exosomal RNA from LCL cells [20]. This finding indicates that $500 \mathrm{pg}$ of EVs was physiologically relevant because at least 100 miRNA copies could suppress target mRNAs in mammalian cells [23]. These reports raised the idea that EVs are small RNA carriers and can be used as a source of effective delivery strategies. There are many reports showing the concept of using EVs for RNA delivery based on the discovery of miRNA transfer (Table 2). In this article, we review the latest reports regarding EVs and the potential for small RNA delivery using EVs. The relevance of EVs and their therapeutic uses are then considered.

\section{Small RNA delivery with EVs}

As shown above, miRNA can be delivered by EVs. Currently, it is well known that miRNA profiling is a valuable diagnostic and prognostic tool for characterizing a wide range of pathologies [24]. Similarly, targeting aberrantly expressed miRNAs offers new therapeutic possibilities [25]. For instance, we demonstrated that injection of miR-16 in tumor-bearing mice suppressed prostate tumor growth by regulating the expression of genes associated with cell cycle control and cellular proliferation such as CDK1 and CDK [26]. In addition, Kota et al. demonstrated that systemic administration of miR-26a in hepatocellular carcinoma-bearing mice using adenoassociated virus suppressed tumor growth without toxicity by downregulating cyclins D2 and E2 [4]. Although many reports show the potential of miRNA for therapeutic purposes, it is quite difficult to decide which types of delivery methods are most appropriate for miRNA because of the limitation in conventional methods such as stability and immunogenicity. Thus, EVs have considerable promise as new delivery systems. There are many reports demonstrating EVs as therapeutic miRNA carriers. We previously demonstrated that the culture supernatant of normal epithelial prostate cells inhibited proliferation of prostate cancer cells in vitro and in vivo [27]. In particular, miR-143, which is a tumor-suppressive miRNA, could induce growth inhibition through downregulation of KRAS and ERK5 expression in prostate cancer cells. Interestingly, the surface of EVs can be modified by the genetic engineering of donor cells for efficient delivery of EVs to target cells. Ohno et al. generated modified EVs derived from

Table 2 List of successful small RNA deliveries by EVs in both basic and clinical research

\begin{tabular}{|c|c|c|c|c|c|}
\hline Small RNA & Target gene & Donor cells & Recipient cells or tissue & Small RNA loading methods & References \\
\hline $\operatorname{miR}-143$ & $\begin{array}{l}\text { KRAS } \\
\text { ERK5 }\end{array}$ & Human normal prostate cell line & Human prostate cancer cell line & $\begin{array}{l}\text { Stable cell lines over-expressing } \\
\text { of miRNA by expressing vector }\end{array}$ & {$[27]$} \\
\hline let-7a & & Human embryonic kidney cell lines & Human breast cancer cell lines & $\begin{array}{l}\text { Lipofection of synthetic miRNA } \\
\text { to donor cells }\end{array}$ & {$[28]$} \\
\hline siRNA & $\begin{array}{l}\text { GAPDH } \\
\text { BACE1 }\end{array}$ & $\begin{array}{l}\text { Murine dendritic cells } \\
\text { Murine dendritic cells }\end{array}$ & $\begin{array}{l}\text { Neurons, microglia, oligodendrocytes } \\
\text { Cortical tissue }\end{array}$ & $\begin{array}{l}\text { Electroporation } \\
\text { Electroporation }\end{array}$ & [29] \\
\hline siRNA & $\begin{array}{l}\mathrm{HCV} \\
\mathrm{CD} 81\end{array}$ & $\begin{array}{l}\text { Human hepatoma cell lines } \\
\text { Human B lymphocytes }\end{array}$ & $\begin{array}{l}\text { Human hepatoma cell lines } \\
\text { Mouse liver cells }\end{array}$ & $\begin{array}{l}\text { Stable cell lines over-expressing } \\
\text { of shRNA by expressing vector }\end{array}$ & {$[30]$} \\
\hline siRNA & MAPK1 & Human peripheral blood cells & Human T cells, monocyte & Electroporation & {$[31]$} \\
\hline
\end{tabular}


the human embryonic kidney cell line HEK293 with the GE11 peptide, which specifically binds to epidermal growth factor receptor (EGFR), or EGF, on their surfaces. These modified EVs can efficiently deliver let-7a miRNA to EGFRexpressing xenografted breast cancer tissue in immunodeficient mice [28]. These observations suggested that EVs can be used for miRNA replacement therapy by restoring the expression of miRNA, which is downregulated in target cells. Conversely, siRNA has been shown to have more specific inhibition compared to miRNA because miRNAs generally have the ability to bind many target mRNAs. Our groups previously reported that not only cellular miRNA but also exogenous siRNA, which is artificial small RNA, can be transported into recipient cells using EVs. This finding suggested that the loading mechanisms of siRNA into EVs are similar to miRNA [22]. Based on these findings, Alvarez-Erviti et al. generated EVs derived from murine immature dendritic cells expressing the membrane protein Lamp2 fused to the neuron-specific rabies viral glycoprotein peptide. Therefore, modified EVs are used as delivery tools into the mouse brain [29]. Interestingly, siRNA against GAPDH can be delivered specifically to neuron microglia and oligodendrocytes in the mouse brain via EVs. Moreover, nonspecific uptake in other tissues was not observed. Furthermore, C57BL/6 normal mice were injected intravenously with siRNA encapsulated in EVs targeting BACE1, which is a strong candidate for anti-Alzheimer's disease. The strong mRNA $(60 \%)$ and protein $(62 \%)$ knockdown of BACE1 was observed in cortical tissue. Pan et al. showed that transmission of siRNA targeting HCV or CD81 was partially mediated by EVs in both human and mouse liver cells in vitro [30]. More importantly, siRNA transmission in vivo was confirmed using immunodeficient mice engrafted with human hepatoma cells producing CD81 siRNA, and consequently, suppression of CD81 expression in mouse hepatocytes was observed. Additionally, Wahlgren et al. showed that MAPK1 siRNA was loaded into the EVs derived from the peripheral blood of healthy donors by electroporation. Then, they confirmed that MAPK1 siRNA in EVs were transferred to human blood cells such as $\mathrm{T}$ cells and monocytes [31]. Taken together, these reports suggest that EVs are a promising application of small RNA delivery. However, further investigation is needed because we are still at an early stage of investigation regarding the nature of EVs.

\section{Potential of EVs to overcome the flaws of conventional delivery systems}

It is conceivable that using EVs as delivery systems has some advantages over conventional carrier systems. First, the contents of EVs can be modified with genetic engineering of the parent cells for efficient delivery of EVs to target cells if required. Kim et al. reported that EVs derived from genetically modified bone marrow-derived dendritic cells expressing FasL, which induces significant antiarthritic effects in mouse, can inhibit inflammation in a murine footpad model of delayed-type hypersensitivity [32]. Secondly, EVs compensate for the shortcomings of conventional drug delivery systems. Adeno-associated virus (AAV) vector is a promising gene delivery vector [33]. However, AAV tends to transduce into liver cells after intravenous delivery, reducing its usefulness for targeted sites [34]. Maguire et al. found that the AAV capsid existed not only as a free particle but also inside EVs, which are termed as "vectosomes," in culture medium after transfection of AAV into 293T cell lines [35]. Furthermore, vectosomes could enhance the gene transfer in human glioblastoma cell lines compared to conventionally purified AAV vectors. Additionally, vectosomes with magnetic beads can be attracted to a magnetized area in human glioblastoma culture cells. These findings suggest that the use of a combination of conventional delivery systems and EVs can be a powerful tool for therapy. Sun et al. demonstrated that the formation of EV-curcumin complexes leads to an increase in the stability of curcumin in vitro and in bioavailability in vivo compared to curcumin only. It is quite interesting to find new therapeutic methods, such as combinations of conventional delivery systems and EVs, for improved therapies.

\section{Critical points that need to be solved in EV-based therapeutics}

Although EVs constitute a novel application for small RNA delivery, some features of EV biology remain unclear.

\section{Stability of EVs}

It is well known that naked siRNA is generally difficult to deliver primarily due to the rapid clearance and the limited serum half-life of 5-60 min of unmodified siRNA [36, 37]. It has been suggested that EVs are relatively stable in the blood because extracellular miRNAs stably exist in human body fluid [6]. In fact, Chen et al. demonstrated that miRNAs in normal human serum under harsh conditions including ten freeze-thaw cycles, low $(\mathrm{pH}=1)$ or high $(\mathrm{pH}=13) \mathrm{pH}$ solution treatment, and DNase treatment yield no significant differences compared to nontreated serum samples [38]. Moreover, Koga et al. reported that miRNAs in EVs were conserved under RNase $(5 \mu \mathrm{g} / \mathrm{ml})$ treatment for $30 \mathrm{~min}$, whereas naked miRNAs were degraded within $30 \mathrm{~min}$ [39]. However, there is one evidence that murine melanoma-derived EVs are rapidly cleared from the blood circulation with a half-life of approximately $2 \mathrm{~min}$ after systemic administration [40]. Therefore, it is essential to know the half-life of EVs in the bloodstream so that the measurement of sequential plasma concentrations of EVs after administration can be used to establish dosage regimens that are 
likely to produce the desired therapeutic levels for appropriate periods of time without the risk of toxicity in EVs.

\section{Components of EVs}

It is important to identify endogenous miRNAs in EVs, which could result in side effects, because EVs contain many kinds of miRNAs [20]. In fact, we previously demonstrated that exosomal miR-210 from metastatic cancer cells could lead the microenvironment of endothelial cells to the benefit of cancer cells promoting cancer metastasis [41]. Moreover, the expression profiles of miRNAs in EVs obtained from metastatic cancer cells demonstrated that a set of angiogenic miRNAs was highly concentrated compared to normal cells. On the other hand, as shown above, our groups reported that supernatant from normal cells inhibited the proliferation of cancer cells [27]. In particular, miR-143 in culture supernatant can induce inhibition of cancer cell growth. From these observations, we propose that enrichment of tumor-suppressive miRNAs can ignore the effects of cancer-promoting miRNAs in EVs. For this reason, knowing the expression profile of miRNAs in EVs is essential. It is also essential that the protein content in EVs be determined by proteomic analysis to identify any endogenous proteins that may mediate potential unwanted side effects. ExoCarta, which is an EV database (http://exocarta.org), provides the exosomal contents that were identified in some organisms. Most exosomal proteins identified thus far are conserved between cell types [42]. In particular, the tetraspanin family including CD9, CD63, CD81, and CD82 has been found in EVs derived from many cell types. However, proteomic analysis by many researchers has proven that the protein content of EVs may vary depending on the host cells. For instance, Blanchard et al. demonstrated that EVs derived from human T cells upon TCR stimulation contain CD3 as a specific marker [14]. If these types of EVs are used for therapeutic purposes, this could induce unwanted immune activation. On the other hand, EVs may contain high amounts of proteins with tumor suppressor properties. In fact, Putz et al. demonstrated that PTEN protein, a tumor suppressor protein, was secreted in EVs, and secreted PTEN was functionally transferred to recipient cells, resulting in the inhibition of cell proliferation through reduction of Akt phosphorylation [43]. These findings indicate that EVs can package specific proteins, which are downregulated in disease and may be used as therapeutic delivery tools. Although the functions of most proteins in EVs are still unknown, further proteomic analysis is important for preventing the harmful side effects of EVs as therapeutic tools.

\section{Purification methods of EVs}

To use EVs as delivery systems for therapy, it is very important to examine the purity of EVs because non-exosomal proteins induce unwanted immune responses. Rood et al. demonstrated that proteins may also contaminate isolated EVs after ultracentrifugation or nanomembrane ultrafiltration preparations from human urine samples [44]. Moreover, Gyorgy et al. reported that preparation of EVs isolated by ultracentrifugation can detect contaminants such as immune complex proteins [45]. Electroporation of EVs with siRNA is accompanied by extensive siRNA aggregation and noncapsulated siRNA from EV surface that cannot be removed before mouse in vivo experiments [46]. Therefore, purification methods such as sucrose cushion, sucrose-iodixanol gradients, or RNase treatment are essential before mouse injection to exclude excess siRNA [47]. In general, EVs are isolated by ultracentrifugation although the yield of EVs is quite low. However, large amounts of EVs are required if EVs are to be used as a therapy resource. Indeed, Mitchell et al. reported a novel culture system by using the CELLine Adhere 1000 (CLAD1000) flask to obtain a high amount of EVs from adherent and nonadherent tumor cells compared to conventional methods [48]. Development of useful and easy methods for significant increasing quantity of EVs is important for usage of EVs as drug delivery cargo. Taken together, it is essential to develop novel isolation methods instead of

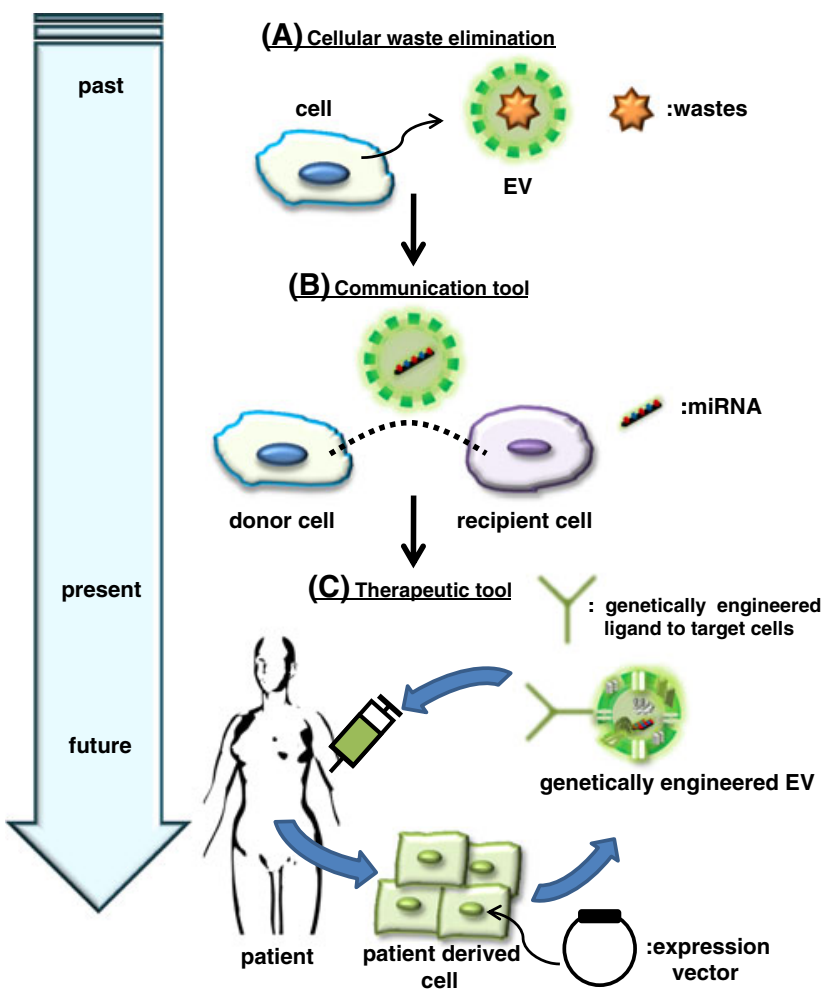

Fig. 1 Schematic representation of the paradigm shift in EVs. Since their discovery, EVs were initially considered to solely be cellular waste elimination systems (a). However, EVs have recently been found to contain both mRNA and miRNA. Additionally, EVs can be transferred between cells, and exosomal miRNAs were functional in recipient cells (b). Therefore, many researchers hope that EVs can be used as novel RNAi delivery systems for human therapy in the near future (c) 
ultracentrifugation to prevent potentially harmful immune responses and to increase the yield of EVs.

\section{Internalization of EVs}

To avoid unwanted delivery, therapeutic EV application requires knowledge of EV uptake mechanisms. There are two possible mechanisms of EV uptake: endocytosis and fusion [49]. However, whether EVs enter cells via endocytosis or fusion remains controversial. Barres et al. demonstrated that uptake of rat reticulocyte EVs by macrophages decreases upon adding galectin-5 [50]. This finding suggests that galectin-5 associates with EV uptake through the endocytic pathway. Moreover, Tian et al. used live-cell microscopy to show that EVs derived from rat pheochromocytomas were internalized by resting rat cells through the endocytosis pathway [51]. Feng et al. reported that EVs from K562 human erythroleukemia or MT4 HTLVtransformed $\mathrm{T}$ cell leukemia are taken up more efficiently by phagocytic cells than non-phagocytic cells because macrophage cells expressed TIM-4, which is one of the receptors to phagocytose EVs [52]. Moreover, dynamin2, which is an important regulator of phagolysosomes, is required for $\mathrm{EV}$ uptake. In addition, Svensson et al. found that uptake of EVs from glioblastoma cells was negatively regulated by the lipid raftassociated protein caveolin-1 through regulation of the ERK1/ 2 signaling pathway [53]. Conversely, Parolini et al. reported that EVs derived from melanoma cells enter melanoma cells through membrane fusion [54]. Further investigation is needed to explain the discrepancies observed in different studies.

\section{Induction of immune response by EVs}

It is essential to investigate whether host-derived EVs induce an immune response with subsequent side effects. Interestingly, there are some evidences that viruses exploit the EV biogenesis pathway for disease spreading. Indeed, Feng et al. reported that the hepatitis A virus uses the host-derived membrane resembling EVs, protecting the virus particles from antibody neutralization and promoting virus spread within the liver [55]. These findings support that host-derived EVs may escape from the immune response. In addition, Narayanan et al. demonstrated that HIV-1infected cells produced EVs containing trans-activation response element (TAR) RNA, which is viral miRNAs. They also showed that TAR RNA in EVs inhibited apoptosis by downregulation of Bim, which is a pro-apoptotic protein, in recipient cells [56]. However, there is some evidence regarding patientderived EV-induced immune response. Alvarez-Erviti et al. reported that both siRNA with EVs or in vivo transfection reagents induce a low immune response in vivo [29]. Moreover, Sun et al. also demonstrated that production levels of IL-6 and TNF- $\alpha$ in the supernatant after stimulation with LPS display no difference between EVs and PBS [57]. In general, induced pluripotent stem cells (iPSCs) cause no immune response because iPSCs are generated from patient cells [58]. However, Zhao et al. reported that the transplantation of immature iPSCs induced a T cell-dependent immune response even in a syngenic mouse [59]. These findings suggested that patient-derived cells have the potential for abnormal gene expression under culture conditions. Therefore, the immunogenicity of therapeutically valuable EVs derived from patient cells should be examined before the initiation of EV clinical applications. Taken together, further studies will be needed to characterize EVs for RNAi therapeutic applications further, and better knowledge of EVs may solve these problems.

\section{Conclusion}

Since EVs were first discovered over 30 years ago, the characterization of their cellular origin and function has been gradually revealed. In particular, the discovery of EVs as natural carriers of miRNA led to the possibility that they can be used as vehicles for the delivery of exogenous therapeutic cargoes. In this review, we summarize the most recent findings regarding EVs for small RNA delivery. Although there are growing concerns about EV small RNA delivery potential, there also exist some limiting factors in clinical translation. However, EVs have some advantages for use as a therapeutic application for small RNA delivery compared to conventional therapy if several issues are resolved (Fig. 1). In conclusion, it is highly likely that EVs will be the application used for novel RNAi delivery systems for human therapy in the near future.

Acknowledgments This work was supported in part by a Grant-in-Aid for the Third-Term Comprehensive 10-Year Strategy for Cancer Control, a Grant-in-Aid for Scientific Research on Priority Areas Cancer from the Ministry of Education, Culture, Sports, Science and Technology; the National Cancer Center Research and Development Fund; the Program for Promotion of Fundamental Studies in Health Sciences of the National Institute of Biomedical Innovation (NiBio); the Project for Development of Innovative Research on Cancer Therapeutics; Grant-in-Aid for JSPS fellows; and the Japan Society for the Promotion of Science (JSPS) through the "Funding Program for World-Leading Innovative R\&D on Science and Technology (FIRST Program)" initiated by the Council for Science and Technology Policy (CSTP).

Conflict of interest All authors declare that they have no conflict of interest.

Open Access This article is distributed under the terms of the Creative Commons Attribution License which permits any use, distribution, and reproduction in any medium, provided the original author(s) and the source are credited.

\section{References}

1. Langer R. Drug delivery and targeting. Nature. 1998;392(6679 Suppl):5. 
2. Lee NS, Dohjima T, Bauer G, Li H, Li M-J, Ehsani A, et al. Expression of small interfering RNAs targeted against HIV-1 rev transcripts in human cells. Nat Biotechnol. 2002;20(5):500-5.

3. Fire A, Xu S, Montgomery MK, Kostas SA, Driver SE, Mello CC. Potent and specific genetic interference by double-stranded RNA in Caenorhabditis elegans. Nature. 1998;391(6669):806-11. doi:10. $1038 / 35888$.

4. Kota J, Chivukula RR, O’Donnell KA, Wentzel EA, Montgomery CL, Hwang H-W, et al. Therapeutic microRNA delivery suppresses tumorigenesis in a murine liver cancer model. Cell. 2009;137(6): 1005-17.

5. Kosaka N, Iguchi H, Ochiya T. Circulating microRNA in body fluid: a new potential biomarker for cancer diagnosis and prognosis. Cancer Sci. 2010;101(10):2087-92.

6. Weber JA, Baxter DH, Zhang S, Huang DY, Huang KH, Lee MJ, et al. The microRNA spectrum in 12 body fluids. Clin Chem. 2010;56(11):1733-41.

7. Kosaka N, Izumi H, Sekine K, Ochiya T. microRNA as a new immune-regulatory agent in breast milk. Silence. 2010;1(1):7. doi: 10.1186/1758-907X-1-7.

8. Mitchell PS, Parkin RK, Kroh EM, Fritz BR, Wyman SK, PogosovaAgadjanyan EL, et al. Circulating microRNAs as stable blood-based markers for cancer detection. Proc Natl Acad Sci. 2008;105(30): 10513-8.

9. Park NJ, Zhou H, Elashoff D, Henson BS, Kastratovic DA, Abemayor E, et al. Salivary microRNA: discovery, characterization, and clinical utility for oral cancer detection. Clin Cancer Res. 2009;15(17):5473-7.

10. Valadi H, Ekstrom K, Bossios A, Sjostrand M, Lee JJ, Lotvall JO. Exosome-mediated transfer of mRNAs and microRNAs is a novel mechanism of genetic exchange between cells. Nat Cell Biol. 2007;9(6):654-9. doi:10.1038/ncb1596.

11. Wolfers J, Lozier A, Raposo G, Regnault A, Théry C, Masurier C, et al. Tumor-derived exosomes are a source of shared tumor rejection antigens for CTL cross-priming. Nat Med. 2001;7(3):297-303.

12. Zitvogel L, Regnault A, Lozier A, Wolfers J, Flament C, Tenza D, et al. Eradication of established murine tumors using a novel cell-free vaccine: dendritic cell derived exosomes. Nat Med. 1998;4(5):594 600.

13. Van Niel G, Raposo G, Candalh C, Boussac M, Hershberg R, CerfBensussan N, et al. Intestinal epithelial cells secrete exosome-like vesicles. Gastroenterology. 2001;121(2):337-49.

14. Blanchard N, Lankar D, Faure F, Regnault A, Dumont C, Raposo G, et al. TCR activation of human $\mathrm{T}$ cells induces the production of exosomes bearing the TCR/CD $3 / \zeta$ complex. J Immunol. 2002;168(7):3235-41.

15. Raposo G, Nijman HW, Stoorvogel W, Liejendekker R, Harding CV, Melief C, et al. B lymphocytes secrete antigen-presenting vesicles. J Exp Med. 1996;183(3):1161-72.

16. György B, Szabó TG, Pásztói M, Pál Z, Misják P, Aradi B, et al. Membrane vesicles, current state-of-the-art: emerging role of extracellular vesicles. Cell Mol Life Sci. 2011;68(16):2667-88.

17. Trams EG, Lauter CJ, Salem Jr N, Heine U. Exfoliation of membrane ecto-enzymes in the form of micro-vesicles. Biochim Biophys Acta. 1981;645(1):63-70.

18. Pan BT, Teng K, Wu C, Adam M, Johnstone RM. Electron microscopic evidence for externalization of the transferrin receptor in vesicular form in sheep reticulocytes. J Cell Biol. 1985;101(3):9428.

19. Bennett M, Gibson D, Schwartz S, Tait J. Binding and phagocytosis of apoptotic vascular smooth muscle cells is mediated in part by exposure of phosphatidylserine. Circ Res. 1995;77(6):1136-42.

20. Pegtel DM, Cosmopoulos K, Thorley-Lawson DA, van Eijndhoven MA, Hopmans ES, Lindenberg JL. Functional delivery of viral miRNAs via exosomes. Proc Natl Acad Sci USA. 2010;107(14): 6328-33. doi:10.1073/pnas.0914843107.
21. Zhang Y, Liu D, Chen X, Li J, Li L, Bian Z. Secreted monocytic miR150 enhances targeted endothelial cell migration. Mol Cell. 2010;39(1):133-44.

22. Kosaka N, Iguchi H, Yoshioka Y, Takeshita F, Matsuki Y, Ochiya T. Secretory mechanisms and intercellular transfer of microRNAs in living cells. J Biol Chem. 2010;285(23):17442-52. doi:10.1074/jbc. M110.107821.

23. Brown BD, Gentner B, Cantore A, Colleoni S, Amendola M, Zingale A, et al. Endogenous microRNA can be broadly exploited to regulate transgene expression according to tissue, lineage and differentiation state. Nat Biotechnol. 2007;25(12):1457-67.

24. Calin GA, Liu C-G, Sevignani C, Ferracin M, Felli N, Dumitru CD, et al. MicroRNA profiling reveals distinct signatures in B cell chronic lymphocytic leukemias. Proc Natl Acad Sci USA. 2004;101(32): 11755-60.

25. Hu S, Huang M, Li Z, Jia F, Ghosh Z, Lijkwan MA, et al. MicroRNA-210 as a novel therapy for treatment of ischemic heart disease. Circulation. 2010;122(11 suppl 1):S124-31.

26. Takeshita F, Patrawala L, Osaki M, Takahashi R-U, Yamamoto Y, Kosaka N, et al. Systemic delivery of synthetic microRNA-16 inhibits the growth of metastatic prostate tumors via downregulation of multiple cell-cycle genes. Mol Ther. 2009;18(1):181-7.

27. Kosaka N, Iguchi H, Yoshioka Y, Hagiwara K, Takeshita F, Ochiya T. Competitive interactions of cancer cells and normal cells via secretory microRNAs. J Biol Chem. 2012;287(2):1397-405. doi:10.1074/ jbc.M111.288662.

28. Ohno S, Takanashi M, Sudo K, Ueda S, Ishikawa A, Matsuyama N. Systemically injected exosomes targeted to EGFR deliver antitumor microRNA to breast cancer cells. Mol Ther. 2013;21(1):185-91. doi: 10.1038/mt.2012.180.

29. Alvarez-Erviti L, Seow Y, Yin H, Betts C, Lakhal S, Wood MJ. Delivery of siRNA to the mouse brain by systemic injection of targeted exosomes. Nat Biotechnol. 2011;29(4):341-5.

30. Pan Q, Ramakrishnaiah V, Henry S, Fouraschen S, de Ruiter PE, Kwekkeboom J. Hepatic cell-to-cell transmission of small silencing RNA can extend the therapeutic reach of RNA interference (RNAi). Gut. 2012;61(9):1330-9. doi:10.1136/gutjnl-2011-300449.

31. Wahlgren J, Karlson TD, Brisslert M, Sani FV, Telemo E, Sunnerhagen $\mathrm{P}$, et al. Plasma exosomes can deliver exogenous short interfering RNA to monocytes and lymphocytes. Nucleic Acids Res. 2012;40(17):e130. doi:10.1093/nar/gks463.

32. Kim SH, Bianco N, Menon R, Lechman ER, Shufesky WJ, Morelli AE. Exosomes derived from genetically modified DC expressing FasL are anti-inflammatory and immunosuppressive. Mol Ther. 2006;13(2):289-300. doi:10.1016/j.ymthe.2005.09.015.

33. Kaplitt MG, Leone P, Samulski RJ, Xiao X, Pfaff DW, O’Malley KL, et al. Long-term gene expression and phenotypic correction using adeno-associated virus vectors in the mammalian brain. Nat Genetics. 1994;8(2):148-54.

34. Koeberl DD, Alexander IE, Halbert CL, Russell DW, Miller AD. Persistent expression of human clotting factor IX from mouse liver after intravenous injection of adeno-associated virus vectors. Proc Natl Acad Sci. 1997;94(4):1426-31.

35. Maguire CA, Balaj L, Sivaraman S, Crommentuijn MH, Ericsson M, Mincheva-Nilsson L, et al. Microvesicle-associated AAV vector as a novel gene delivery system. Mol Ther. 2012;20:960-71.

36. Takakura Y, Nishikawa M, Yamashita F, Hashida M. Development of gene drug delivery systems based on pharmacokinetic studies. Eur J Pharm Sci. 2001;13(1):71-6.

37. Soutschek J, Akinc A, Bramlage B, Charisse K, Constien R, Donoghue $\mathrm{M}$. Therapeutic silencing of an endogenous gene by systemic administration of modified siRNAs. Nature. 2004;432(7014): $173-8$.

38. Chen X, Ba Y, Ma L, Cai X, Yin Y, Wang K, et al. Characterization of microRNAs in serum: a novel class of biomarkers for diagnosis of cancer and other diseases. Cell Res. 2008;18(10):997-1006. 
39. Koga Y, Yasunaga M, Moriya Y, Akasu T, Fujita S, Yamamoto S, et al. Exosome can prevent RNase from degrading microRNA in feces. J Gastrointestinal Oncol. 2011;2(4):215.

40. Takahashi Y, Nishikawa M, Shinotsuka H, Matsui Y, Ohara S, Imai T, et al. Visualization and in vivo tracking of the exosomes of murine melanoma B16-BL6 cells in mice after intravenous injection. J Biotechnol. 2013;165:77-84.

41. Kosaka N, Iguchi H, Hagiwara K, Yoshioka Y, Takeshita F, Ochiya T. Neutral sphingomyelinase 2 (nSMase2)-dependent exosomal transfer of angiogenic microRNAs regulate cancer cell metastasis. J Biol Chem. 2013;288(15):10849-59.

42. Mathivanan S, Simpson RJ. ExoCarta: a compendium of exosomal proteins and RNA. Proteomics. 2009;9(21):4997-5000.

43. Putz U, Howitt J, Doan A, Goh C-P, Low L-H, Silke J, et al. The tumor suppressor PTEN is exported in exosomes and has phosphatase activity in recipient cells. Sci Signal. 2012;5(243): ra70.

44. Rood IM, Deegens JK, Merchant ML, Tamboer WP, Wilkey DW, Wetzels JF, et al. Comparison of three methods for isolation of urinary microvesicles to identify biomarkers of nephrotic syndrome. Kidney Int. 2010;78(8):810-6.

45. György B, Módos K, Pállinger É, Pálóczi K, Pásztói M, Misják P, et al. Detection and isolation of cell-derived microparticles are compromised by protein complexes resulting from shared biophysical parameters. Blood. 2011;117(4):e39-48.

46. Kooijmans SA, Stremersch S, Braeckmans K, de Smedt S, Hendrix A, Wood MJ, et al. Electroporation-induced siRNA precipitation obscures the efficiency of siRNA loading into extracellular vesicles. J Control Release. 2013;172:229-38.

47. Cantin R, Diou J, Bélanger D, Tremblay AM, Gilbert C. Discrimination between exosomes and HIV-1: purification of both vesicles from cell-free supernatants. J Immunol Methods. 2008;338(1):2130 .

48. Mitchell JP, Mason MD, Tabi Z, Clayton A. Increased exosome production from tumour cell cultures using the Integra CELLine Culture System. J Immunol Methods. 2008;335(1):98-105.
49. Morelli AE, Larregina AT, Shufesky WJ, Sullivan ML, Stolz DB, Papworth GD, et al. Endocytosis, intracellular sorting, and processing of exosomes by dendritic cells. Blood. 2004;104(10):3257-66.

50. Barres C, Blanc L, Bette-Bobillo P, Andre S, Mamoun R, Gabius HJ. Galectin-5 is bound onto the surface of rat reticulocyte exosomes and modulates vesicle uptake by macrophages. Blood. 2010;115(3):696705. doi:10.1182/blood-2009-07-231449.

51. Tian T, Wang Y, Wang H, Zhu Z, Xiao Z. Visualizing of the cellular uptake and intracellular trafficking of exosomes by live-cell microscopy. J Cell Biochem. 2010;111(2):488-96. doi:10.1002/jcb.22733.

52. Feng D, Zhao WL, Ye YY, Bai XC, Liu RQ, Chang LF, et al. Cellular internalization of exosomes occurs through phagocytosis. Traffic. 2010;11(5):675-87.

53. Svensson KJ, Christianson HC, Wittrup A, Bourseau-Guilmain E, Lindqvist E, Svensson LM, et al. Exosome uptake depends on ERK1/ 2-heat shock protein 27 signaling and lipid raft-mediated endocytosis negatively regulated by caveolin-1. J Biol Chem. 2013;288(24): 17713-24

54. Parolini I, Federici C, Raggi C, Lugini L, Palleschi S, De Milito A. Microenvironmental $\mathrm{pH}$ is a key factor for exosome traffic in tumor cells. J Biol Chem. 2009;284(49):34211-22.

55. Feng Z, Hensley L, McKnight KL, Hu F, Madden V, Ping L, et al. A pathogenic picornavirus acquires an envelope by hijacking cellular membranes. Nature. 2013;496(7445):367-71.

56. Narayanan A, Iordanskiy S, Das R, Van Duyne R, Santos S, Jaworski $\mathrm{E}$ et al. Exosomes derived from HIV-1 infected cells contain TAR RNA. Journal of Biological Chemistry. 2013.

57. Sun D, Zhuang X, Xiang X, Liu Y, Zhang S, Liu C, et al. A novel nanoparticle drug delivery system: the anti-inflammatory activity of curcumin is enhanced when encapsulated in exosomes. Mol Ther. 2010;18(9):1606-14.

58. Takahashi K, Yamanaka S. Induction of pluripotent stem cells from mouse embryonic and adult fibroblast cultures by defined factors. Cell. 2006;126(4):663-76.

59. Zhao T, Zhang Z-N, Rong Z, Xu Y. Immunogenicity of induced pluripotent stem cells. Nature. 2011;474(7350):212-5. 